\title{
Recent developments in the clinical pharmacology of rolapitant: subanalyses in specific populations
}

This article was published in the following Dove Press journal:

Drug Design, Development and Therapy

5 September 2017

Number of times this article has been viewed

\author{
Bernardo Leon Rapoport ${ }^{1}$ \\ Matti Aapro \\ Martin R Chasen ${ }^{3}$ \\ Karin Jordan ${ }^{4}$ \\ Rudolph M Navari ${ }^{5}$ \\ lan Schnadig \\ Lee Schwartzberg ${ }^{7}$ \\ 'The Medical Oncology Centre \\ of Rosebank, Johannesburg, South \\ Africa; ${ }^{2}$ Breast Center, Genolier \\ Cancer Center, Genolier, Switzerland; \\ ${ }^{3}$ Palliative Care, William Osler Health \\ Services, Brampton, ON, Canada; \\ ${ }^{4}$ Department of Medicine $\mathrm{V}$, University \\ of Heidelberg, Heidelberg, Germany; \\ ${ }^{5}$ Division of Hematology Oncology, \\ University of Alabama School of \\ Medicine, Birmingham, AL, USA; \\ ${ }^{6}$ Compass Oncology, US Oncology \\ Research, Tualatin, OR, USA; ${ }^{7}$ West \\ Clinic, Memphis, TN, USA
}

Correspondence: Bernardo Leon Rapoport

The Medical Oncology Centre of Rosebank, 129 Oxford Road, Corner Northwold, Saxonwold Johannesburg, 2196, South Africa Tel +27 I I 8804169 Email brapoport@rosebankoncology. co.za

\begin{abstract}
Knowledge of the involvement of the neurokinin substance P in emesis has led to the development of the neurokinin-1 receptor antagonists (NK-1 RAs) for control of chemotherapyinduced nausea and vomiting (CINV), in combination with serotonin type 3 receptor antagonists and corticosteroids. The NK-1 RA rolapitant, recently approved in oral formulation, has nanomolar affinity for the NK-1 receptor, as do the other commercially available NK-1 RAs, aprepitant and netupitant. Rolapitant is rapidly absorbed and has a long half-life in comparison to aprepitant and netupitant. All three NK-1 RAs undergo metabolism by cytochrome P450 (CYP) 3A4, necessitating caution with the concomitant use of CYP3A4 inhibitors, but in contrast to aprepitant and netupitant, rolapitant does not inhibit or induce CYP3A4. However, rolapitant is a moderate inhibitor of CYP2D6, and concomitant use with CYP2D6 substrates with narrow therapeutic indices should be avoided. Aprepitant, netupitant, and rolapitant have all demonstrated efficacy in the control of delayed CINV in patients receiving moderately and highly emetogenic chemotherapy in randomized controlled trials, including over multiple cycles of chemotherapy. We reviewed recent post hoc analyses of clinical trial data demonstrating that rolapitant is efficacious in the control of CINV in patient populations with specific tumor types, namely, breast cancers, gastrointestinal/colorectal cancers, and lung cancers. In addition, we show that rolapitant has efficacy in the control of CINV in specific age groups of patients receiving chemotherapy ( $<65$ and $\geq 65$ years of age). Overall, the safety profile of rolapitant in these specific patient populations was consistent with that observed in primary analyses of phase 3 trials.
\end{abstract}

Keywords: rolapitant, neurokinin-1 receptor antagonist, chemotherapy-induced nausea and vomiting, post hoc analyses

\section{Introduction to the management of chemotherapy- induced nausea and vomiting (CINV)}

Nausea and vomiting are the side effects most feared by patients undergoing cytotoxic chemotherapies. ${ }^{1-3}$ The 5-day at-risk period for CINV typically manifests in two distinct phases. The acute phase, which occurs during the first 24 hours after chemotherapy, is largely mediated by free radical-induced serotonin (5-hydroxytryptamine [5-HT]) release in the small intestine and consequent activation of 5-HT type $3\left(5-\mathrm{HT}_{3}\right)$ receptors located on vagal terminals in the gut wall. ${ }^{4-6}$ The delayed phase of CINV starts on day 2 after chemotherapy, can last until day 5, and is predominantly mediated by a central pathway that involves binding of the mammalian tachykinin family neurotransmitter/neuromodulator, substance $\mathrm{P}$, to neurokinin-1 (NK-1) receptors located in the brainstem. ${ }^{4,5,7}$

CINV in the acute phase is reasonably well-managed in the majority of patients by $5-\mathrm{HT}_{3}$ receptor antagonists, such as palonosetron, which also has activity in the 
delayed phase. ${ }^{8,9}$ However, full control of delayed-phase CINV still presents a treatment challenge.

Other medications have also been used in the treatment of CINV. Corticosteroids such as dexamethasone are used in combination with 5-HT 3 antagonists for the control of acute CINV, and either alone or in combination with NK-1 receptor antagonists for control of delayed CINV, ${ }^{10-13}$ although their mechanism of action is not well understood. ${ }^{14}$ Dopamine type 2 receptors are present in the brainstem nuclei involved in triggering emesis; the earliest agents used in control of emesis were dopamine antagonists such as the phenothiazines (chlorpromazine) and butyrophenones (haloperidol). However, extrapyramidal symptoms and other adverse effects have limited the use of these agents, ${ }^{5,15}$ expert opinion and current National Comprehensive Cancer Network guidelines recommend the use of dopamine antagonists such as haloperidol or metoclopramide in the treatment of established and breakthrough nausea and emesis. ${ }^{5,12}$ The atypical antipsychotic olanzapine has antagonistic actions at a range of dopamine and serotonin receptors, including dopamine type 2 and 5- $\mathrm{HT}_{3}$ receptors, and in a recent trial it was shown to be superior to placebo when added to a combination of a $5-\mathrm{HT}_{3}$ antagonist, dexamethasone, and an NK-1 receptor antagonist for the complete control of nausea (defined as a response of 0 on a visual analog scale [VAS] with a maximum of 10). In patients receiving highly emetogenic chemotherapy (HEC), the percentage with no nausea (response of 0 on the VAS) significantly improved compared with control in the acute phase ( $74 \%$ vs $45 \% ; P=0.002)$, delayed phase ( $42 \%$ vs $25 \%$; $P=0.002)$, and overall phase (days 1 to 5$)(37 \%$ vs $22 \%$; $P=0.002)$; the proportions of patients with complete responses were also superior after olanzapine-containing regimens vs placebo in the acute ( $86 \%$ vs $65 \%$; $P<0.001$ ), delayed ( $67 \%$ vs $52 \% ; P=0.007)$, and overall phases ( $64 \%$ vs $41 \% ; P<0.001){ }^{16}$ Current Multinational Association of Supportive Care in Cancer/European Society for Medical Oncology guidelines recommend the use of olanzapine for breakthrough nausea and emesis and as first-line prophylaxis for HEC. ${ }^{13}$

Advances in the understanding of the role played by substance $\mathrm{P}$ in emesis has led to the investigation and development of NK-1 receptor antagonists for the control of delayed-phase CINV. Aprepitant was the first oral NK-1 antagonist to be approved, in 2003, and was followed by fosaprepitant, a pro-drug of aprepitant in an intravenous (IV) formulation, and netupitant, formulated as a fixed oral combination with palonosetron; casopitant was not approved. Rolapitant has been recently approved in an oral formulation and is currently under US Food and Drug Administration
(FDA) review in a bioequivalent IV formulation. ${ }^{17}$ Herein we review the clinical pharmacology and efficacy of rolapitant in the context of the other NK-1 receptor antagonists, as well as the clinical efficacy of rolapitant in subpopulations of chemotherapy patients with specific tumor types.

\section{Clinical pharmacology of NK-I receptor antagonists NK-I receptor affinity and occupancy}

In vitro studies have shown that rolapitant binds with high affinity to the human NK-1 receptor $(\mathrm{Ki}, 0.66 \mathrm{nmol} / \mathrm{L})$ and has $>1,000$-fold selectivity for the NK-1 receptor vs NK-2 and NK-3 receptor subtypes. ${ }^{18}$ The affinity of netupitant at the human NK-1 receptor is also in the nanomolar range $(1.0 \mathrm{nmol} / \mathrm{L}),{ }^{19}$ while aprepitant displaces $50 \%$ of substance $\mathrm{P}$ from human NK-1 receptors at a concentration of $0.12 \mathrm{nmol} / \mathrm{L} .{ }^{20}$ Positron emission tomography (PET) data have shown that plasma concentrations of rolapitant of $348 \mathrm{ng} / \mathrm{mL}$ correspond to $>90 \% \mathrm{NK}-1$ receptor occupancy, and that such plasma concentrations are observed with the recommended $180 \mathrm{mg}$ dose of oral rolapitant. ${ }^{21}$ Receptor occupancy levels $>90 \%$ were also achieved with $300 \mathrm{mg}$ oral netupitant, $125 \mathrm{mg}$ oral aprepitant, and $150 \mathrm{mg}$ IV fosaprepitant in PET studies. ${ }^{22-25}$ This level of occupancy was maintained 96 hours after administration of netupitant ${ }^{24}$ and 120 hours after administration of rolapitant, ${ }^{21}$ suggesting that a single dose of either of these two compounds would provide protective efficacy against delayed-phase CINV. However, it has been predicted that a single $125 \mathrm{mg}$ dose of oral aprepitant will maintain $>90 \%$ receptor occupancy for 24 hours only, necessitating further dosing (at $80 \mathrm{mg}$ /day) on days 2 and 3 post-chemotherapy. ${ }^{22}$

\section{Pharmacokinetic properties of NK-I receptor antagonists}

Rolapitant is rapidly absorbed in healthy individuals, with its mean peak plasma concentration reaching $968 \mathrm{ng} / \mathrm{mL}$ 4 hours following a single $180 \mathrm{mg}$ oral dose, and has a bioavailability of approximately $100 \% \cdot{ }^{26,27}$ Administration of aprepitant, fosaprepitant, and netupitant to healthy volunteers resulted in mean peak plasma concentrations of $1,539 \mathrm{ng} / \mathrm{mL}$ (4 hours after $125 \mathrm{mg}$ dose on day 1) to $1,356 \mathrm{ng} / \mathrm{mL}$ (4 hours after $80 \mathrm{mg}$ dose on day 3), 4,200 ng/mL (aprepitant concentration within 30 minutes of $150 \mathrm{mg}$ IV infusion of fosaprepitant), and $434 \mathrm{ng} / \mathrm{mL}$ (5 hours after $300 \mathrm{mg}$ dose), respectively, with bioavailabilities of at least $59 \%{ }^{28-32}$ The half-life of rolapitant is $169-183$ hours ${ }^{26}$ substantially longer than that of aprepitant (9-13 hours following either oral 
aprepitant or IV fosaprepitant $)^{29,30}$ or netupitant ( 80 hours in cancer patients). ${ }^{24,28}$

Rolapitant is metabolized primarily by cytochrome $\mathrm{P} 450$ (CYP) 3A4, forming the active metabolite M19, and chronic concomitant use of strong inducers of CYP3A4 should therefore be avoided; ${ }^{26}$ conversely, neither rolapitant nor M19 has any inductive or inhibitory effect on CYP3A4. ${ }^{33}$ Oral rolapitant inhibits the breast cancer resistance protein transporter and the P-glycoprotein transporter and moderately inhibits CYP2D6. Monitoring for adverse events is recommended if concomitant use with substrates of breast cancer resistance protein, P-glycoprotein, or CYP2D6 with narrow therapeutic windows cannot be avoided; concomitant use of the CYP2D6 substrate pimozide should be avoided and concomitant use with thioridazine is contraindicated. ${ }^{26}$ It should be noted that rolapitant in IV formulation does not significantly inhibit the breast cancer resistance protein transporter nor the P-glycoprotein transporter. ${ }^{34}$

Aprepitant is metabolized primarily by CYP3A4, as well as by CYP1A2 and CYP2C19; caution should be used regarding concomitant administration of CYP3A4 inhibitors, and strong inducers of this enzyme should be avoided. ${ }^{29,35}$ In addition, aprepitant is both a weak to moderate dose-dependent inhibitor and weak inducer of CYP3A4, and also an inducer of CYP2C9; hence, concomitant use of benzodiazepines, chemotherapeutic substrates of CYP3A4, and CYP2C9 substrates (such as warfarin) should be carefully monitored. Dose reductions in corticosteroids (dexamethasone) are necessary and may be necessary when coadministering benzodiazepines, depending on the clinical situation. ${ }^{29,36-38}$

Netupitant is metabolized by and acts as a moderate inhibitor of CYP3A4, and increases exposure to CYP3A4 substrates midazolam, erythromycin, and dexamethasone. Dose reductions in dexamethasone are required, and may be necessary when coadministering other CYP3A4 substrates; caution and adverse event monitoring is recommended in patients receiving chemotherapeutic substrates of CYP3A4. Use of strong CYP3A4 inducers with netupitant should be avoided. ${ }^{28,39}$

\section{Clinical efficacy of NK-I receptor antagonists Aprepitant/fosaprepitant and netupitant}

The efficacy of NK-1 receptor antagonists for prevention of delayed CINV when used in combination with a $5-\mathrm{HT}_{3}$ receptor antagonist and a corticosteroid has been established in a number of randomized controlled trials; these trials were conducted by comparison of the addition of the respective $\mathrm{NK}-1$ receptor antagonist to a $5 \mathrm{HT}_{3}$ antagonist/ corticosteroid combination vs the addition of placebo to the same combination (active control). When using the proportion of patients with a complete response (no emesis and no use of rescue medication) in the delayed phase of cycle 1 of chemotherapy treatment as an endpoint, aprepitant was superior to active control in two studies that enrolled patients receiving cisplatin-based HEC (75\% vs 56\% and $68 \%$ vs $47 \%$ in each study, respectively; $P<0.001$ for both comparisons), ${ }^{40,41}$ and in two studies that enrolled patients receiving moderately emetogenic chemotherapy (MEC) or doxorubicin/cyclophosphamide-based chemotherapy (67\% vs $32 \% ; P<0.05$ and $71 \%$ vs $61 \% ; P<0.01$, respectively). ${ }^{42,43}$ Fosaprepitant was shown to be superior to active control for the same endpoint measure in patients receiving cisplatinbased HEC (65\% vs 49\%; $P=0.0025)^{44}$ and MEC (79\% vs $69 \% ; P<0.001),{ }^{45}$ and non-inferiority to aprepitant was also demonstrated (fosaprepitant vs aprepitant, $74 \%$ vs $74 \%$ ). ${ }^{46}$ Netupitant (administered in combination with palonosetron) was also superior to active control for complete response during the delayed phase of cycle 1 in patients receiving anthracycline and cyclophosphamide (AC)-based chemotherapy $(77 \%$ vs $70 \% ; P=0.001),{ }^{47}$ and in patients receiving cisplatin-based chemotherapy $(90 \%$ vs $80 \% ; P<0.05) .{ }^{48}$

\section{Rolapitant}

All trials evaluating efficacy have been performed with oral rolapitant; however, the IV formulation has been shown to be bioequivalent ${ }^{17}$ and is currently under review by the FDA. Complete response rates during the acute, delayed, and overall phases of the first cycle of HEC and MEC in trials of rolapitant are shown in Table 1. Rolapitant was superior to active control for complete response rates in the delayed and overall phases of two trials that enrolled patients receiving $\mathrm{HEC},{ }^{49}$ and one trial that enrolled patients receiving MEC or AC-based regimens. ${ }^{50}$ Complete response rates in the acute phase were also superior in patients receiving rolapitant vs active control after administration of HEC, but not MEC/AC. The benefit of rolapitant is also sustained over multiple cycles of chemotherapy in patients receiving $\mathrm{HEC}$ or $\mathrm{MEC} / \mathrm{AC}$, as demonstrated in a pooled analysis of these trials. ${ }^{51}$

\section{Clinical efficacy of rolapitant - subanalyses in specific populations Tumor types - breast, gastrointestinal (Gl)/colorectal, and lung cancers}

To evaluate the efficacy and safety of rolapitant in various tumor types, post hoc analyses have recently been carried out 
Table I Complete response (\%) in total population by phase and chemotherapy treatment following oral administration of rolapitant

\begin{tabular}{|c|c|c|c|c|}
\hline & MEC or AC trial, $\%^{50}$ & $P$-value & $\begin{array}{l}\text { HECI and HEC2 trials; } \\
\text { cisplatin-based, } \%^{49}\end{array}$ & $P$-value \\
\hline & ROL $(n=666)$ vs CON $(n=666)$ & & ROL $(n=535)$ vs CON $(n=535)$ & \\
\hline Acute phase $(0-24 \mathrm{~h})$ & 83.5 vs 80.3 & 0.1425 & 83.6 vs 76.6 & 0.0045 \\
\hline Delayed phase (24-120 h) & 71.3 vs 61.6 & 0.0002 & 71.4 vs 60.2 & 0.0001 \\
\hline Overall phase $(0-120 \mathrm{~h})$ & 68.6 vs 57.8 & $<0.0001$ & 68.8 vs 58.5 & 0.0005 \\
\hline
\end{tabular}

Abbreviations: AC, anthracycline and cyclophosphamide; CON, control; h, hours; HEC, highly emetogenic chemotherapy; MEC, moderately emetogenic chemotherapy; ROL, rolapitant.

on clinical trial data from patients receiving chemotherapy for breast cancers, GI and colorectal cancers, and lung cancers. In breast cancer patients who were enrolled in the phase 3 trial of rolapitant for CINV induced by MEC or AC-based regimens, ${ }^{50}$ complete response rates were greater with rolapitant than with active control in the overall ( $62.8 \%$ vs $55.1 \% ; P=0.023)$ and delayed phases $(66.7 \%$ vs $59.8 \% ; P=0.039)$ (Table 2$)$, as were no emesis rates, although no significant differences were observed in the endpoints of no nausea (Table 3) or no significant nausea. ${ }^{52}$ As $80 \%$ of this group of patients received AC-based chemotherapy, analyses were also carried out on just those patients receiving AC-based regimens, and similar findings to the overall breast cancer population regarding the endpoints of complete response (Table 2), no nausea (Table 3 ), and no significant nausea were reported.

Patients who enrolled in three previous trials of rolapitant who were receiving chemotherapy for GI or colorectal cancer were included in two post hoc analyses. Data were pooled from the two trials of patients who received cisplatin-based HEC for the first analysis, ${ }^{49}$ and complete response rates were significantly higher in patients who received rolapitant compared to active control in the delayed $(72.2 \%$ vs $48.0 \%$; $P=0.012)$ and overall phases ( $72.2 \%$ vs $48.0 \% ; P=0.012)$ (Table 2).$^{53}$ For the endpoint of no emesis, rolapitant was superior to active control in both the delayed and overall phases, and was also superior in the overall (but not delayed) phase for the endpoint of no nausea (Table 3). For the second analysis, data were drawn from the trial of rolapitant in patients who received MEC or AC-based chemotherapies, ${ }^{50}$ but only those patients who received MEC were included; the most commonly used non-AC agents were irinotecan (rolapitant, $68.1 \%$ of patients; placebo, $70.3 \%$ of patients) and oxaliplatin ( $27.7 \%$ and $21.6 \%$ of patients, respectively). Complete response rates were higher in the acute $(91.5 \%$ vs $73.0 \% ; P=0.025$ ) (Tesaro, Inc., data on file, 2016) and overall phases $(74.5 \%$ vs $48.6 \% ; P=0.016)$ of CINV in patients receiving rolapitant, and numerically but not significantly higher in the delayed phase $(74.5 \%$ vs $54.1 \%$; $P=0.052$ ) (Table 2). ${ }^{53}$ Rates of no nausea were significantly higher in patients receiving rolapitant in the delayed and overall phases (Table 3), while rates of no emesis were higher in both the delayed and overall phases but in neither phase was this difference significant.

For analysis of rolapitant benefits in patients receiving chemotherapy for lung cancer, data were pooled from the same three previous trials. ${ }^{49,50}$ The majority of patients received cisplatin (rolapitant, $70.0 \%$ of patients; placebo, $65.7 \%$ of patients) while almost all of the remaining patients received carboplatin $(29.4 \%$ and $32.6 \%$ of patients, respectively). Rolapitant significantly improved complete response rates compared to active control in the acute $(88.4 \%$ vs $81.7 \% ; P=0.014)$, delayed ( $77.4 \%$ vs $65.1 \% ; P<0.001)$, and overall phases ( $75.4 \%$ vs $63.1 \% ; P<0.001)$ of CINV in these patients (Table 2); no emesis rates were also improved in all phases, while no nausea rates were improved in the delayed and overall, but not acute phases (Table 3). ${ }^{54}$

\section{Elderly patients}

To investigate the efficacy of rolapitant in elderly and younger patients, data were drawn from the three previous trials of rolapitant, and were stratified based on patient age ( $<65$ years vs $\geq 65$ years) and type of chemotherapy (HEC vs MEC or AC-based chemotherapy). ${ }^{49,50}$ The majority of patients receiving cisplatin-based HEC in both age groups were male ( $<65$ years: rolapitant, $59.9 \%$ and active control, $63.1 \%$; $\geq 65$ years, rolapitant, $71.7 \%$ and active control, $62.0 \%$ ), whereas male patients were the minority of those who received MEC or AC-based chemotherapy ( $<65$ years: rolapitant, $14.7 \%$ and active control, $12.1 \%$; $\geq 65$ years: rolapitant, $36.3 \%$ and active control, 37.2\%). The median ages of patients in the age $<65$ years stratification from each treatment arm of each of the HEC and MEC studies ranged from 52 to 56 years, with the youngest patient included aged 18 years. In this younger age group, complete response rates were superior in the delayed and overall phases in patients receiving rolapitant, both after cisplatin-based HEC (delayed: $71.3 \%$ vs $59.8 \% ; P<0.001$; overall: 68.0 vs $58.5 \% ; P=0.006$ ) and MEC/AC-based regimens (delayed: $70.3 \%$ vs $60.9 \%$; 

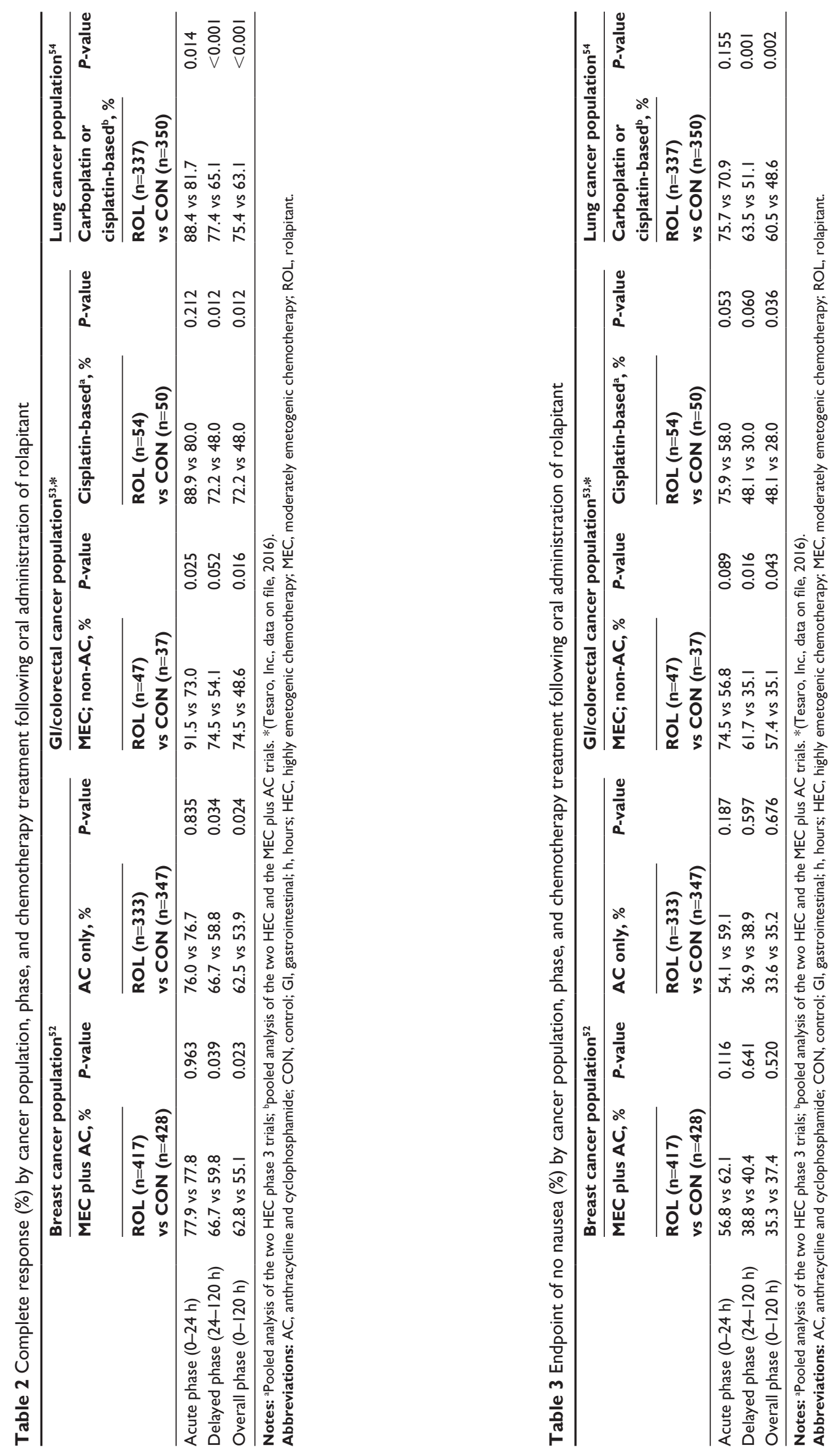
Table 4 Complete response (\%) by age, phase, and chemotherapy treatment following oral administration of rolapitant ${ }^{55,56}$

\begin{tabular}{|c|c|c|c|c|c|c|c|c|}
\hline & \multicolumn{4}{|c|}{ Patients $<65$ years old } & \multicolumn{4}{|l|}{ Patients $\geq 65$ years old } \\
\hline & MEC plus AC, $\%$ & $P$-value & Cisplatin-based $^{\mathrm{a}}, \%$ & $P$-value & MEC- or AC-based, \% & $P$-value & Cisplatin-based $^{\mathrm{a}}, \%$ & $P$-value \\
\hline & $\begin{array}{l}\text { ROL }(n=495) \\
\text { vs CON }(n=470)\end{array}$ & & $\begin{array}{l}\text { ROL }(n=397) \\
\text { vs CON }(n=393)\end{array}$ & & $\begin{array}{l}\text { ROL }(n=|7|) \\
\text { vs CON }(n=196)\end{array}$ & & $\begin{array}{l}\text { ROL }(n=138) \\
\text { vs CON }(n=142)\end{array}$ & \\
\hline Acute phase $(0-24 \mathrm{~h})$ & 81.8 vs 77.9 & 0.127 & 81.9 vs 76.8 & 0.082 & 88.3 vs 86.2 & 0.553 & 88.4 vs 76.1 & 0.007 \\
\hline Delayed phase $(24-120 \mathrm{~h})$ & 70.3 vs 60.9 & 0.002 & 71.3 vs 59.8 & $<0.001$ & 74.3 vs 63.3 & 0.024 & 71.7 vs 61.3 & 0.064 \\
\hline Overall phase $(0-120 \mathrm{~h})$ & 67.5 vs 56.6 & $<0.00 \mathrm{I}$ & 68.0 vs 58.5 & 0.006 & 71.9 vs 60.7 & 0.024 & 71.0 vs 58.5 & 0.028 \\
\hline
\end{tabular}

Note: aPooled analysis of the two HEC phase 3 trials.

Abbreviations: AC, anthracycline and cyclophosphamide; CON, control; h, hours; HEC, highly emetogenic chemotherapy; MEC, moderately emetogenic chemotherapy; ROL, rolapitant.

$P=0.002$; overall: $67.5 \%$ vs $56.6 \% ; P<0.001$ ) (Table 4). ${ }^{55,56}$ For the endpoints of no emesis and no nausea (Table 5), rolapitant was superior in the younger age group for the delayed and overall phases in patients who received cisplatinbased HEC; rolapitant was also superior for no emesis in the delayed and overall phases for MEC/AC-treated patients, but not for the endpoint of no nausea. ${ }^{56}$

The median ages of patients in the age $\geq 65$ years stratification from each treatment arm of each of the HEC and MEC studies ranged from 68 to 70 years, with the oldest patient included aged 90 years. Patients in this older age group who had received cisplatin-based HEC had complete response rates that were higher in the acute $(88.4 \%$ vs $76.1 \% ; P=0.007)$ and overall phases $(71.0 \%$ vs $58.5 \%$; $P=0.028$ ), while higher rates observed in the delayed phase were not statistically significant $(71.7 \%$ vs $61.3 \% ; P=0.064)$ (Table 4). ${ }^{55,56}$ However, in older patients who received MEC or AC-based regimens, complete response rates were higher for rolapitant in the delayed $(74.3 \%$ vs $63.3 \% ; P=0.024)$ and overall ( $71.9 \%$ vs $60.7 \% ; P=0.024)$, but not the acute phases ( $88.3 \%$ vs $86.2 \% ; P=0.553)$. In this age group, patients who received cisplatin-based HEC showed improved rates of no emesis after rolapitant in all CINV phases, and improved rates of no nausea in the acute phase (Table 5); in older patients who received $\mathrm{MEC}$ or $\mathrm{AC}$-based regimens, greater rates of no emesis were observed in the delayed and overall phases, while no effect of rolapitant was observed for the endpoint of no nausea. ${ }^{56}$

\section{Conclusion}

In post hoc analyses, rolapitant has shown superiority over active control for prevention of CINV over the full 5-day atrisk period in patient populations receiving HEC and MEC specifically for breast, GI/colorectal, and lung cancers, and in populations stratified by age ( $<65$ and $\geq 65$ years). For delayed-phase CINV, rolapitant was also superior to active placebo in these specific populations, although not to statistical significance in patients receiving non-AC MEC regimens for $\mathrm{GI} /$ colorectal cancers nor in patients aged $\geq 65$ years receiving cisplatin-based HEC regimens. These results are consistent with the findings of the overall phase 3 clinical trials, and provide additional information about the potential therapeutic utility of rolapitant in specific populations. In the post hoc analyses, the incidence of adverse events was generally similar in the rolapitant and placebo arms, and the safety profile of rolapitant was consistent with the safety data from the primary analysis of the phase 3 trials. It should be noted that oral netupitant with palonosetron and oral aprepitant are FDA-approved alternative NK-1 receptor antagonists for control of CINV.

Table 5 Endpoint of no nausea (\%) by age, phase, and chemotherapy treatment following oral administration of rolapitant ${ }^{55,56}$

\begin{tabular}{|c|c|c|c|c|c|c|c|c|}
\hline & \multicolumn{4}{|c|}{ Patients $<65$ years old } & \multicolumn{4}{|c|}{ Patients $\geq 65$ years old } \\
\hline & MEC plus AC, $\%$ & $P$-value & Cisplatin-based $^{a}, \%$ & $P$-value & MEC plus AC, $\%$ & $P$-value & Cisplatin-based $^{\text {a }}, \%$ & $P$-value \\
\hline & $\begin{array}{l}\text { ROL }(n=495) \\
\text { vs CON }(n=470)\end{array}$ & & $\begin{array}{l}\text { ROL }(n=397) \\
\text { vs CON }(n=393)\end{array}$ & & $\begin{array}{l}\text { ROL }(n=|7|) \\
\text { vs CON }(n=196)\end{array}$ & & $\begin{array}{l}\text { ROL }(n=138) \\
\text { vs CON }(n=142)\end{array}$ & \\
\hline Acute phase $(0-24 \mathrm{~h})$ & 60.4 vs 61.9 & 0.630 & 67.3 vs 62.8 & 0.194 & 78.4 vs 75.5 & 0.519 & 79.7 vs 68.3 & 0.030 \\
\hline Delayed phase $(24-120$ h) & 44.6 vs 42.1 & 0.430 & 54.7 vs 42.5 & $<0.001$ & 59.6 vs 51.5 & 0.119 & 58.7 vs 49.3 & 0.115 \\
\hline Overall phase $(0-120 \mathrm{~h})$ & 41.2 vs 38.5 & 0.392 & 50.9 vs 39.9 & 0.002 & 57.9 vs 50.5 & 0.157 & 56.5 vs 46.5 & 0.093 \\
\hline
\end{tabular}

Note: aPooled analysis of the two HEC phase 3 trials.

Abbreviations: AC, anthracycline and cyclophosphamide; CON, control; h, hours; HEC, highly emetogenic chemotherapy; MEC, moderately emetogenic chemotherapy; ROL, rolapitant. 


\section{Acknowledgments}

Medical writing and editorial support were provided by Ruggero Galici, PhD, Jeremy Kennard, PhD, and Paula Stuckart of Ashfield Healthcare Communications, and funded by Tesaro.

\section{Disclosure}

M Aapro reports the following conflicts of interest: Consulting or advisory role: Helsinn Healthcare, Teva, Hospira, Merck KGaA, Merck, Sandoz, Pierre Fabre Medicament, Vifor Pharma, and Tesaro. Speakers' bureau: Amgen, Helsinn Healthcare, Teva, Novartis, Roche, Johnson \& Johnson, Hospira, Sandoz, Pierre Fabre Medicament, Vifor Pharma, and Tesaro. Expert testimony: Amgen. Honoraria: Amgen. Research funding: Helsinn Healthcare, Sandoz, Hospira, Novartis, and Pierre Fabre Medicament.

L Schwartzberg reports the following conflicts of interest: Consulting or advisory role: Eisai, Teva, Amgen, Genentech, and Bristol-Myers Squibb. Leadership: Vector Oncology. Speakers' bureau: Genentech, Novartis, and Bristol-Myers Squibb. Stock and other ownership interests: Vector Oncology. Research funding: Eisai.

$\mathrm{K}$ Jordan reports the following conflicts of interest: Consulting or advisory role: Merck, MSD, Helsinn Healthcare, and Tesaro.

BL Rapoport reports the following conflicts of interest: Honoraria and expenses: Tesaro, Merck and Co and Herron. Advisory boards: Tesaro, Merck and Co and Herron. Funded research: Merck and Co and Tesaro.

I Schnadig reports the following conflict of interest: Advisory board for Tesaro. MR Chasen and RM Navari report no conflicts of interest in this work.

\section{References}

1. Beusterien K, Grinspan J, Kuchuk I, et al. Use of conjoint analysis to assess breast cancer patient preferences for chemotherapy side effects. Oncologist. 2014;19(2):127-134.

2. Sun CC, Bodurka DC, Weaver CB, et al. Rankings and symptom assessments of side effects from chemotherapy: insights from experienced patients with ovarian cancer. Support Care Cancer. 2005;13(4):219-227.

3. Vidall C, Fernandez-Ortega P, Cortinovis D, Jahn P, Amlani B, Scotte F. Impact and management of chemotherapy/radiotherapy-induced nausea and vomiting and the perceptual gap between oncologists/oncology nurses and patients: a cross-sectional multinational survey. Support Care Cancer. 2015;23(11):3297-3305.

4. Hesketh PJ. Chemotherapy-induced nausea and vomiting. N Engl J Med. 2008;358(23):2482-2494.

5. Navari RM. The safety of antiemetic medications for the prevention of chemotherapy-induced nausea and vomiting. Expert Opin Drug Saf. 2016;15(3):343-356.

6. Rudd JA, Andrews PL. Mechanisms of acute, delayed and anticipatory emesis induced by anticancer therapies. In: Hesketh PJ, editor. Management of nausea and vomiting in cancer and cancer treatment. Sudbury, MA: Jones and Bartlett Publishers; 2005:15-66.
7. Saito R, Takano Y, Kamiya HO. Roles of substance P and NK(1) receptor in the brainstem in the development of emesis. J Pharmacol Sci. 2003;91(2):87-94.

8. Jordan K, Jahn F, Aapro M. Recent developments in the prevention of chemotherapy-induced nausea and vomiting (CINV): a comprehensive review. Ann Oncol. 2015;26(6):1081-1090.

9. Navari RM, Aapro M. Antiemetic prophylaxis for chemotherapy-induced nausea and vomiting. $N$ Engl J Med. 2016;374(14):1356-1367.

10. Basch E, Prestrud AA, Hesketh PJ, et al. Antiemetics: American Society of Clinical Oncology clinical practice guideline update. J Clin Oncol. 2011;29(31):4189-4198.

11. Hesketh PJ, Bohlke K, Lyman GH, et al. Antiemetics: American Society of Clinical Oncology focused guideline update. J Clin Oncol. 2016;34(4):381-386.

12. National Comprehensive Cancer Network. NCCN clinical practice guidelines in oncology: antiemesis. Version 2. NCCN; 2016. Available from: https://www.nccn.org/professionals/physician_gls/ pdf/antiemesis.pdf. Accessed February 3, 2017.

13. Roila F, Molassiotis A, Herrstedt J, et al. 2016 MASCC and ESMO guideline update for the prevention of chemotherapy- and radiotherapyinduced nausea and vomiting and of nausea and vomiting in advanced cancer patients. Ann Oncol. 2016;27(suppl 5):v119-v133.

14. Barbour SY. Corticosteroids in the treatment of chemotherapy-induced nausea and vomiting. J Natl Compr Canc Netw. 2012;10(4):493-499.

15. Nandeesh BR, Reddy TM. Chemotherapy induced nausea \& vomiting (CINV). Int J Basic Clin Pharmacol. 2012;1(3):125-131.

16. Navari RM, Qin R, Ruddy KJ, et al. Olanzapine for the prevention of chemotherapy-induced nausea and vomiting. $N$ Engl J Med. 2016;375(2):134-142.

17. Wang X, Zhang ZY, Arora S, et al. A single-dose bioequivalence study of rolapitant following oral and intravenous administration in healthy volunteers. Support Care Cancer. 2016;24(suppl 1):S74.

18. Duffy RA, Morgan C, Naylor R, et al. Rolapitant (SCH 619734): a potent, selective and orally active neurokinin NK1 receptor antagonist with centrally-mediated antiemetic effects in ferrets. Pharmacol Biochem Behav. 2012;102(1):95-100.

19. Rizzi A, Campi B, Camarda V, et al. In vitro and in vivo pharmacological characterization of the novel $\mathrm{NK}_{1}$ receptor selective antagonist Netupitant. Peptides. 2012;37(1):86-97.

20. Huskey SE, Dean BJ, Bakhtiar R, et al. Brain penetration of aprepitant, a substance P receptor antagonist, in ferrets. Drug Metab Dispos. 2003;31(6):785-791.

21. Wang X, Zhang ZY, Powers D, Wang J, Lu S, Kansra V. Rolapitant absolute bioavailability and PET imaging studies in healthy adult volunteers. Clin Pharmacol Ther. Epub 2017 Jan 31.

22. Bergstrom M, Hargreaves RJ, Burns HD, et al. Human positron emission tomography studies of brain neurokinin 1 receptor occupancy by aprepitant. Biol Psychiatry. 2004;55(10):1007-1012.

23. Hargreaves R. Imaging substance P receptors (NK1) in the living human brain using positron emission tomography. J Clin Psychiatry. 2002; 63(suppl 11):18-24.

24. Spinelli T, Calcagnile S, Giuliano C, et al. Netupitant PET imaging and ADME studies in humans. J Clin Pharmacol. 2014;54(1):97-108.

25. Van Laere K, De Hoon J, Bormans G, et al. Equivalent dynamic human brain NK1-receptor occupancy following single-dose i.v. fosaprepitant vs. oral aprepitant as assessed by PET imaging. Clin Pharmacol Ther. 2012;92(2):243-250.

26. Varubi ${ }^{\mathrm{TM}}$ (rolapitant) tablets for oral use [package insert]. Waltham, MA: TESARO, Inc.; 2015.

27. Zhang ZY, Wang X, Powers D, et al. Absorption, metabolism, and excretion of rolapitant, a highly selective and long-acting NK-1 antagonist, in healthy volunteers. Drug Metab Rev. 2016;48(suppl 1):50.

28. Akynzeo ${ }^{\circledR}$ (netupitant and palonosetron) capsules, for oral use [package insert]. Switzerland: Helsinn Healthcare SA; 2015. 
29. Emend $d^{\circledR}$ (aprepitant) capsules and Emend ${ }^{\circledR}$ for oral suspension [package insert]. Whitehouse Station, NJ: Merck Sharp \& Dohme Corp.; 2015.

30. Emend (fosaprepitant dimeglumine) for injection, for intravenous use [package insert]. Whitehouse Station, NJ: Merck Sharp \& Dohme Corp.; 2016.

31. Majumdar AK, Howard L, Goldberg MR, et al. Pharmacokinetics of aprepitant after single and multiple oral doses in healthy volunteers. J Clin Pharmacol. 2006;46(3):291-300.

32. Akynzeo $300 \mathrm{mg} / 0.5 \mathrm{mg}$ hard capsules. Summary of product characteristics. Helsinn Birex Pharmaceuticals Ltd. Available from: http://www.ema.europa.eu/docs/en_GB/document_library/ EPAR_-_Product_Information/human/003728/WC500188432.pdf. Accessed April 3, 2017.

33. Poma A, Christensen J, Pentikis H, Arora S, Hedley M. Rolapitant and its major metabolite do not affect the pharmacokinetics of midazolam, a sensitive cytochrome P450 3A4 substrate. Support Care Cancer. 2013;21(suppl 1):S154.

34. Wang J, Wang X, Zhang ZY, et al. Effects of rolapitant administered intravenously on the pharmacokinetics of digoxin (P-gp) and sulfasalazine (BCRP) in healthy volunteers. Support Care Cancer. 2016; 24(suppl 1):S89.

35. Sanchez RI, Wang RW, Newton DJ, et al. Cytochrome P450 3A4 is the major enzyme involved in the metabolism of the substance $\mathrm{P}$ receptor antagonist aprepitant. Drug Metab Dispos. 2004;32(11):1287-1292.

36. Aapro MS, Walko CM. Aprepitant: drug-drug interactions in perspective. Ann Oncol. 2010;21(12):2316-2323.

37. Shadle CR, Lee Y, Majumdar AK, et al. Evaluation of potential inductive effects of aprepitant on cytochrome P450 3A4 and 2C9 activity. J Clin Pharmacol. 2004;44(3):215-223.

38. Majumdar AK, McCrea JB, Panebianco DL, et al. Effects of aprepitant on cytochrome P450 3A4 activity using midazolam as a probe. Clin Pharmacol Ther. 2003;74(2):150-156.

39. Lanzarotti C, Rossi G. Effect of netupitant, a highly selective $\mathrm{NK}_{1}$ receptor antagonist, on the pharmacokinetics of midazolam, erythromycin, and dexamethasone. Support Care Cancer. 2013;21(10):2783-2791.

40. Hesketh PJ, Grunberg SM, Gralla RJ, et al. The oral neurokinin-1 antagonist aprepitant for the prevention of chemotherapy-induced nausea and vomiting: a multinational, randomized, double-blind, placebocontrolled trial in patients receiving high-dose cisplatin - the Aprepitant Protocol 052 Study Group. J Clin Oncol. 2003;21(22):4112-4119.

41. Poli-Bigelli S, Rodrigues-Pereira J, Carides AD, et al. Addition of the neurokinin 1 receptor antagonist aprepitant to standard antiemetic therapy improves control of chemotherapy-induced nausea and vomiting. Results from a randomized, double-blind, placebo-controlled trial in Latin America. Cancer. 2003;97(12):3090-3098.

42. Gralla RJ, de Wit R, Herrstedt J, et al. Antiemetic efficacy of the neurokinin-1 antagonist, aprepitant, plus a 5HT3 antagonist and a corticosteroid in patients receiving anthracyclines or cyclophosphamide in addition to high-dose cisplatin: analysis of combined data from two Phase III randomized clinical trials. Cancer. 2005;104(4):864-868.

43. Rapoport BL, Jordan K, Boice JA, et al. Aprepitant for the prevention of chemotherapy-induced nausea and vomiting associated with a broad range of moderately emetogenic chemotherapies and tumor types: a randomized, double-blind study. Support Care Cancer. 2010; 18(4):423-431.

44. Saito H, Yoshizawa H, Yoshimori K, et al. Efficacy and safety of singledose fosaprepitant in the prevention of chemotherapy-induced nausea and vomiting in patients receiving high-dose cisplatin: a multicentre, randomised, double-blind, placebo-controlled phase 3 trial. Ann Oncol. 2013; 24(4):1067-1073.
45. Weinstein C, Jordan K, Green SA, et al. Single-dose fosaprepitant for the prevention of chemotherapy-induced nausea and vomiting associated with moderately emetogenic chemotherapy: results of a randomized, double-blind phase III trial. Ann Oncol. 2016;27(1):172-178.

46. Grunberg S, Chua D, Maru A, et al. Single-dose fosaprepitant for the prevention of chemotherapy-induced nausea and vomiting associated with cisplatin therapy: randomized, double-blind study protocol EASE. J Clin Oncol. 2011;29(11):1495-1501.

47. Aapro M, Rugo H, Rossi G, et al. A randomized phase III study evaluating the efficacy and safety of NEPA, a fixed-dose combination of netupitant and palonosetron, for prevention of chemotherapy-induced nausea and vomiting following moderately emetogenic chemotherapy. Ann Oncol. 2014;25(7):1328-1333.

48. Hesketh PJ, Rossi G, Rizzi G, et al. Efficacy and safety of NEPA, an oral combination of netupitant and palonosetron, for prevention of chemotherapy-induced nausea and vomiting following highly-emetogenic chemotherapy: a randomized dose-ranging pivotal study. Ann Oncol. 2014;25(7):1340-1346.

49. Rapoport BL, Chasen MR, Gridelli C, et al. Safety and efficacy of rolapitant for prevention of chemotherapy-induced nausea and vomiting after administration of cisplatin-based highly emetogenic chemotherapy in patients with cancer: two randomised, active-controlled, double-blind, phase 3 trials. Lancet Oncol. 2015;16(9):1079-1089.

50. Schwartzberg LS, Modiano MR, Rapoport BL, et al. Safety and efficacy of rolapitant for prevention of chemotherapy-induced nausea and vomiting after administration of moderately emetogenic chemotherapy or anthracycline and cyclophosphamide regimens in patients with cancer: a randomised, active-controlled, double-blind, phase 3 trial. Lancet Oncol. 2015;16(9):1071-1078.

51. Rapoport B, Schwartzberg L, Chasen M, et al. Efficacy and safety of rolapitant for prevention of chemotherapy-induced nausea and vomiting over multiple cycles of moderately or highly emetogenic chemotherapy. Eur J Cancer. 2016;57:23-30.

52. Schwartzberg L, Navari R, Arora S, Powers D, Jordan K, Rapoport B. Rolapitant for prevention of chemotherapy-induced nausea and vomiting (CINV) in patients with breast cancer. Poster presented at: Multinational Association of Supportive Care in Cancer/International Society of Oral Oncology annual meeting on supportive care in cancer; June 25; 2016; Adelaide, Australia.

53. Navari R, Jordan K, Rapoport BL, et al. Efficacy of rolapitant for prevention of chemotherapy-induced nausea and vomiting (CINV) in patients with gastrointestinal and colorectal cancers. Poster presented at: European Society for Medical Oncology; October 9; 2016; Copenhagen, Denmark.

54. Navari R, Rapoport B, Arora S, Powers D, Jordan K, Schwartzberg L. Rolapitant for control of chemotherapy-induced nausea and vomiting (CINV) in patients with lung cancer. Poster presented at: Multinational Association of Supportive Care in Cancer/International Society of Oral Oncology annual meeting on supportive care in cancer; June 25; 2016; Adelaide, Australia.

55. Aapro M, Arora S, Powers D. Rolapitant for prevention of chemotherapyinduced nausea and vomiting (CINV) in patients aged $<65$ vs $\geq$ 65 years. Poster presented at: Multinational Association of Supportive Care in Cancer/International Society of Oral Oncology annual meeting on supportive care in cancer; June 23; 2016; Adelaide, Australia.

56. Aapro MS, Arora S, Powers D. Efficacy and safety of rolapitant in the prevention of chemotherapy-induced nausea and vomiting (CINV) in elderly patients. Poster presented at: European Society for Medical Oncology; October 9; 2016; Copenhagen, Denmark. 
Drug Design, Development and Therapy

Dovepress

\section{Publish your work in this journal}

Drug Design, Development and Therapy is an international, peerreviewed open-access journal that spans the spectrum of drug design and development through to clinical applications. Clinical outcomes, patient safety, and programs for the development and effective, safe, and sustained use of medicines are the features of the journal, which

has also been accepted for indexing on PubMed Central. The manuscript management system is completely online and includes a very quick and fair peer-review system, which is all easy to use. Visit http://www.dovepress.com/testimonials.php to read real quotes from published authors.

Submit your manuscript here: http://www.dovepress.com/drug-design-development-and-therapy-journal 